\title{
Formação de Biofilmes por Staphylococcus Aureus e Pseudomonas Aeruginosa em Diferentes Superfícies Utilizadas em Indústrias de Alimentos
}

Karine Angélica Dalla Costa (I), Mariane Ferenz (I), Janaira Santana Nunes (II), Eduardo Alves (II), Sheila Mello da Silveira (I), Alessandra Farias Millezi (I)

(I) IFC - Instituto Fedral Catarinense - Câmpus Concórdia (Rodovia SC 283 - Km 08 - Vila Fragosos - Concórdia - SC), (II) UFLA - Universidade Federal de Lavras (Lavras)

\section{Resumo}

Biofilmes são comunidades microbianas constituídas por células sésseis, mono ou multiespécies, aderidas superfícies embebidas numa matriz de polímeros extracelulares (exopolissacarídeos - EPS). As bactérias frequentemente produzem biofilme, algumas apresentam, naturalmente, maior aptidão que outras. Nas indústrias de alimentos, a existência de biofilmes é bastante problemática, sendo responsável por prejuízos de ordem econômica e contaminações dos alimentos. Consequentemente, pesquisas envolvendo a caracterização da capacidade de formação de biofilmes microbianos são relevantes para posteriormente desenvolver formas inovadoras, criativas e eficientes para o controle dessas comunidades microbianas. O objetivo deste trabalho foi analisar a formação de biofilmes por bactérias patogênicas e/ou deteriorantes sobre diferentes superfícies. Avaliou-se o crescimento das células planctônicas e a formação de biofilme de Pseudomonas aeruginosa ATCC 27853 e Staphylococcus aureus ATCC 29213 em condições laboratoriais similares às encontradas na indústria de alimentos, utilizando o aço inoxidável AISI 304 e polipropileno como superfícies de contato e analisou-se a arquitetura dos biofilmes microbianos por Microscopia Eletrônica de Varredura (MEV). Os biofilmes foram incubados em shake orbital (Tecnal, Brasil) à $37^{\circ} \mathrm{C}$ sob agitação constante de $110 \mathrm{rpm}$, em recipientes separados

\footnotetext{
Referência:

Karine Angélica Dalla Costa, Mariane Ferenz, Janaira Santana Nunes, Eduardo Alves, Sheila Mello da Silveira, Alessandra Farias Millezi.Formação de Biofilmes por Staphylococcus Aureus e Pseudomonas Aeruginosa em Diferentes Superfícies Utilizadas em Indústrias de Alimentos. In: Anais do 12 Congresso Latinoamericano de Microbiologia e Higiene de Alimentos - MICROAL 2014 [= Blucher Food Science Proceedings, num.1, vol.1]. São Paulo: Editora Blucher, 2014. 
contendo o meio Trypticase Soy Broth (TSB) com o inoculo padronizado (10 8 UFC mL-1). Os cupons (20x8x1 mm) ficaram suspensos por fios metálicos esterilizados. Após 24 horas realizou-se a contagem das células sésseis aderidas nos cupons e a quantificação das células planctônicas presentes no meio. As maiores contagens de células viáveis em biofilme ocorreram para P. aeruginosa sendo $7.34 \log 10 \mathrm{UFC} / \mathrm{cm}^{2}$ em aço e 7.32 $\log 10 \mathrm{UFC} / \mathrm{cm}^{2}$ em polipropileno, assim como de células planctônicas (9.34 $\log 10 \mathrm{UFC} / \mathrm{mL}$ ). Staphylococcus aureus apresentou $4.75 \log 10$ $\mathrm{UFC} / \mathrm{cm}^{2}$ em aço e $5.30 \log 10 \mathrm{UFC} / \mathrm{cm}^{2}$ em polipropileno, já a contagem de células planctônicas alcançou $7.88 \log 10 \mathrm{UFC} / \mathrm{mL}$. Estatisticamente verificou-se que houve diferença significativa nas contagens das células de P. aeruginosa e $S$. aureus (PP. aeruginosa. Nesse estudo concluiu-se que P. aeruginosa foi a bactéria com maior capacidade de formação de biofilme nas superfícies de aço e polipropileno.

Palavras-Chave: formação de biofilmes, bactérias patogênicas, aço inoxidável, polipropileno, indústria de alimentos

Agência de Fomento: Conselho Nacional de Desenvolvimento Científico e Tecnológico (CNPq). 